\title{
CONSTRUCTION OPERATION SIMULATION TOOL - COST
}

\author{
Tao-ming Cheng ${ }^{1}$, Shien-Tang $\mathrm{Wu}^{2}$, and Yi-Wei Tseng ${ }^{2}$ \\ ${ }^{1}$ Associate Professor, Department of Construction Engineering, Chaoyang \\ University of Technology, Taiwan \\ ${ }^{2}$ Graduate Student, Department of Construction Engineering, Chaoyang \\ University of Technology, Taiwan
}

\begin{abstract}
As a simulation methodology, CYCLONE has been widely used in the design and analysis of construction operation for over the last 20 years. MicroCYCLONE, as the implementation computer program of CYCLONE, had a great contribution in the promotion of CYCLONE. However, MicroCYCLONE is a DOS-based program and has not been improved since the existence of Windows-based computer operation system. This paper aims to introduce a new simulation program named as Construction Operation Simulation Tool (COST). It was developed using Visual Basic programming language based on CYCLONE methodology. COST not only updates the MicroCYCLONE program, but provides fuzzy data simulation function that facilitates the modeling uncertainty.

Keywords: Construction Operation Simulation, CYCLONE Methodology, Fuzzy Set Theory, Fuzzy Data.
\end{abstract}

\section{INTRODUCTION}

As a simulation system/methodology, CYCLONE (CYCLic Operation NEtwork) has been widely used in the design and analysis of construction operation for over the last 20 years $[1,2,3,4,5,6,7]$. There are two major reasons that make CYCLONE popular. One is that CYCLONE provides clear and simple symbols that can be easily used compared to other simulation systems such as SLAM II. The other is that the development of MicroCYCLONE which is the implementation computer software of CYCLONE. In the promotion of CYCLONE, MicroCYCLONE had a great contribution. However, MicroCYCLONE is a DOS-based software and has not been improved since Windows-based computer operation systems have been invented. That makes MicroCYCLONE obsolete. This paper aims to present a new Construction Operation Simulation Tool (COST) that was developed using Visual Basic programming language based on CYCLONE modeling methodology.

\section{EXISTING SIMULATION TOOLS SPECIFIED FOR CONSTRUCTION OPERATION ANALYSIS}

There exist a couple of simulation tools specified for construction operation analysis such as MicroCYCLONE, UM-CYLONE, COOPS, DISCO, and STROBOSCOPE $[6,7,8,9,10]$. These tools form a so-called CYCLONE "family" since the symbols used to represent different functions in the aforementioned simulation tools are similar to those used in CYCLONE. However, in the CYCLONE family, only MicroCYCLONE and DISCO truly adopt CYCLONE methodology as their core engine for running simulation analysis.

MicroCYCLONE and DISCO were obsolete since computer hardware and software were created. MicroCYCLONE was developed under a DOS environment and therefore its use is constrained by DOS memory. The memory constraint limits the cycles that can be run in the MicroCYCLONE. Disco adopts window input and output interface which creates a more friendly user interface that allows users to avoid learning the MicroCYCLONE program which transfers CYCLONE network into a MicroCYCLONE readable program. However, DISCO was designed to use MicroCYCLONE as a core engine for running simulation analysis. That makes DISCO still constrained by DOC memory as DOS does in MicroCYCLONE. Since CYCLONE has been widely used, improving or developing new computer tools that adopt CYCLONE methodology is necessary.

\section{INTRODUCTION OF COST}




\subsection{COST Program}

COST is developed based on CYCLONE modeling methodology, which readers may refer to Halpin and Riggs for details. COST is written by Microsoft Visual Basic language and run under Windows operating environment.

The input of a CYCLONE model is designed through dialogue boxes as shown in Fig. 1. The simulation outputs are designed to show tabular and graphical form simultaneously shown in Fig. 2. Table 1 lists the types of reports provided by the COST program. Examples of the process summary report and element report provided by COST are shown in Fig. 3 and Fig. 4 respectively. The major features that differentiate COST from MicroCYCLONE and DISCO are depicted in Table 2.

There are two substantial functions, provided by COST, which are optimization and fuzzy data simulation. Resources required by activities can be changed due to their availability or some other circumstances. The combinations of different resources will generate different system production or productivity. COST can run the sensitivity analysis and then suggest the best combinations of resources that have the maximum system productivity. The capability of simulating fuzzy data of COST is discussed in the next section.

Table 1 COST Report Types

\begin{tabular}{|c|c|c|c|c|c|}
\hline & $\begin{array}{c}\text { Nor- } \\
\text { mal }\end{array}$ & Combi & Queue & $\begin{array}{c}\text { Conso- } \\
\text { lidate }\end{array}$ & $\begin{array}{l}\text { Count- } \\
\text { er }\end{array}$ \\
\hline profile & $\mathrm{V}$ & $\mathrm{V}$ & $\mathrm{V}$ & $\mathrm{V}$ & \\
\hline $\begin{array}{c}\% \text { time busy } \\
\text { (idle) }\end{array}$ & $\mathrm{V}$ & $\mathrm{V}$ & $\mathrm{V}$ & & \\
\hline $\begin{array}{c}\text { system } \\
\text { productivity }\end{array}$ & & & & & $\mathrm{V}$ \\
\hline $\begin{array}{c}\text { best 5 } \\
\text { productivity } \\
\text { in sensitivity } \\
\text { analysis }\end{array}$ & & & $\mathrm{v}$ & & $\mathrm{V}$ \\
\hline
\end{tabular}

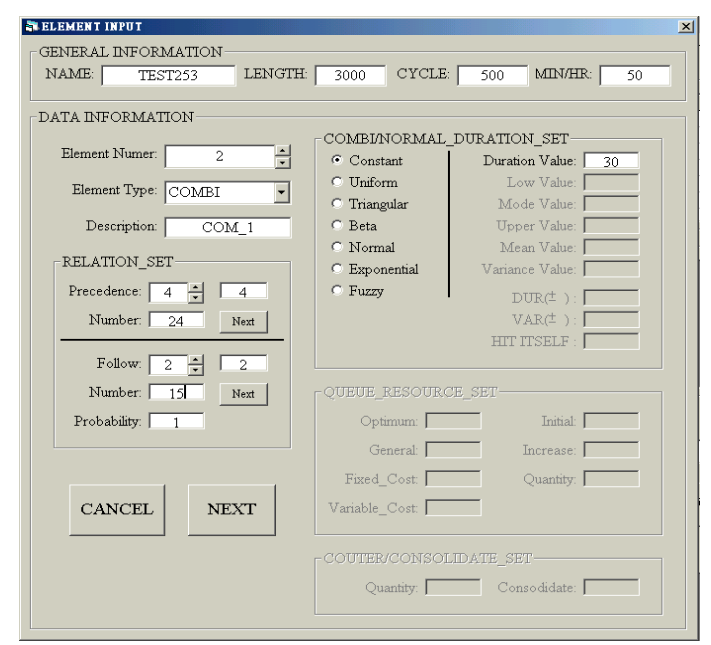

Fig. 1 Input Interface Provided by COST
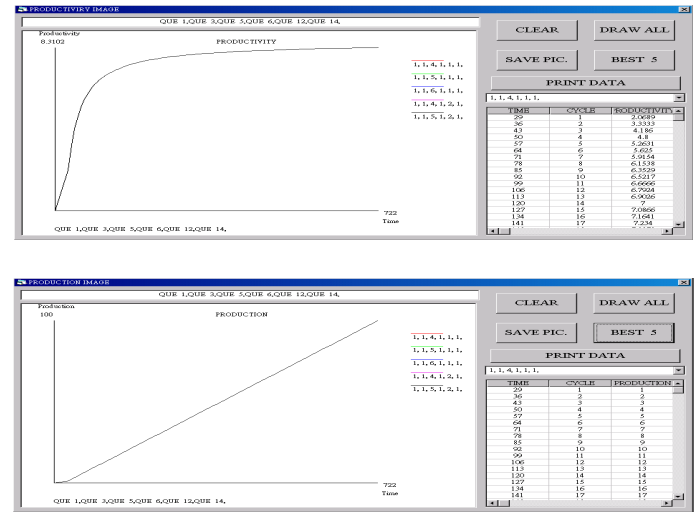

Fig. 2 Graphical Output Interface

Table 2 Comparison of COST, MicroCYCLONE, and DISCO

\begin{tabular}{|c|c|c|c|}
\hline Item & COST & $\begin{array}{c}\text { Micro- } \\
\text { CYCLONE }\end{array}$ & DISCO \\
\hline input interface & dialogue & program & $\begin{array}{c}\text { abstract } \\
\text { model }\end{array}$ \\
\hline $\begin{array}{c}\text { cycles } \\
\text { limitation }\end{array}$ & yes & no & no \\
\hline Optimization & yes & no & n \\
\hline fuzzy data & yes & no & no \\
\hline
\end{tabular}

\subsection{Fuzzy Modeling Function}

Traditionally, probability theory is used to model the uncertainty of activity duration. However, choosing a right probability distribution requires collection of specific amount of data. Then, in order to judge whether the data is a good fit for certain types of probability distribution, the data has to be tested by some statistical techniques such as ChiSquare test. In the construction environment, collecting a large amount of data of the same activity tends to be unrealistic. Therefore, that makes an obstacle for stochastic simulation in construction operation analysis. In such a case, fuzzy set theory that has no demand for a large amount of historical data collection becomes an option for modeling the uncertainty of activity duration.

\begin{tabular}{|c|c|}
\hline FTROCESS SUMMARY & \\
\hline SUMMY & VAULE \\
\hline \multicolumn{2}{|l|}{ PROCESS SUMMY: } \\
\hline RUN LENGTH(minutes) & 722 \\
\hline NUMBER OF CYCLES & 100 \\
\hline UNITS PRODUCED PER CYCLE & 1 \\
\hline TOTAL PRODUCTION (Units) & 100 \\
\hline UNITS PRODUCED PER HOUR & 8.3102 \\
\hline \multicolumn{2}{|l|}{ COST SUMMY: } \\
\hline HOURLY PRODUCTION (Units/Hr) & 8.3102 \\
\hline TOTAL VARLABLE COST (\$) & 1805 \\
\hline TOTAL FLXED COST (\$) & 6979.3333 \\
\hline TOTAL COST (\$) & 8784.3333 \\
\hline COST PER UNIT (\$) & 87.8433 \\
\hline \multicolumn{2}{|l|}{ QUE 1,QUE 3,QUE 5,QUE 6,QUE 12,QUE 14 , } \\
\hline |2UE 1- 1,QUE 3-1,QUE 5- 4,QUE 6-1,QUE 12-1,' & PRUI \\
\hline
\end{tabular}

Fig. 3 Process Summary Report

COST provides fuzzy duration estimation function. The membership function used in COST is triangular. Users only have to input three parameters 
that are lower/upper and mode values that represent the support and core of a triangular membership function respectively. In the final data output, COST would defuzzificate the fuzzy data into a single real number via center of sums methodology. A fuzzy data input example is depicted in Fig. 5 schematically.

\section{APPLICATION EXAMPLE}

\subsection{Base Case Scenario}

The sample CYCLONE network of earthmoving operation is taken from Halpin and Riggs (1992, page 360) as shown in Fig. 6. Soils are formed as stock pile via a dozer. Front-end loader takes soils from the pile, then dumps the soil into the truck. After loading, truck moves to dump. When it arrives at dump zone, truck dumps under the assistance of a spotter. A dump dozer will spread the soils. The descriptions of each node, initial resource quantities, and activity duration shown in Fig. 6 are listed in Table 3.

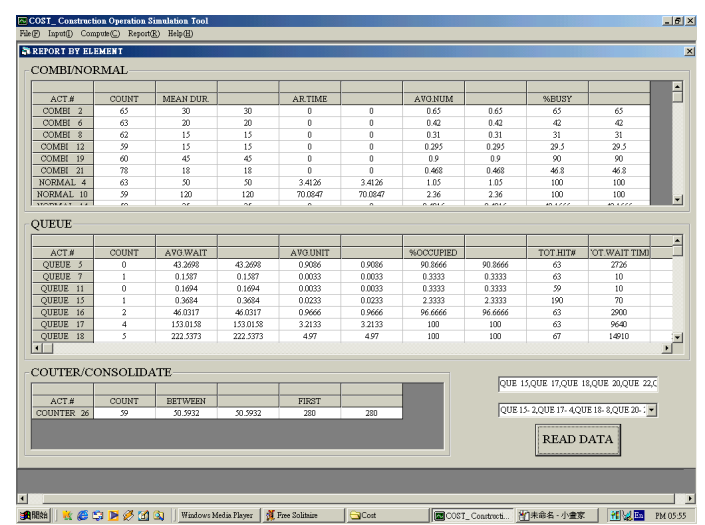

Fig. 4 Element Report

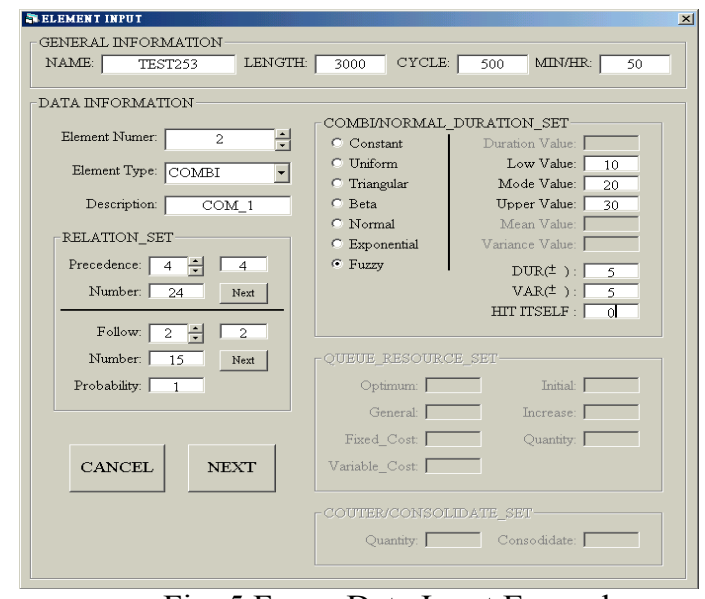

Fig. 5 Fuzzy Data Input Example

\subsection{Simulation Result Comparison}

In order to check the correctness of the COST program, the activity durations are all set to be fixed. The model ran for 100 cycles. The comparison of simulation output ran from COST and MicroCYCLONE are detailed in Table 4. There is no difference of certain types of outputs between those generated by COST and MicroCYCLONE. However, the executed time for COST is faster than required for MicroCYCLONE.

Table 3 The List of Node Description

\begin{tabular}{|c|c|c|c|}
\hline Node & Description & $\begin{array}{c}\text { Initial } \\
\text { Resource }\end{array}$ & $\begin{array}{l}\text { Activity } \\
\text { Duration }\end{array}$ \\
\hline 1 & soil & 1 & - \\
\hline 2 & $\begin{array}{c}\text { stock pile } \\
\text { soil }\end{array}$ & & $5 \mathrm{~min}$. \\
\hline 3 & dozer & 1 & - \\
\hline 4 & $\begin{array}{c}\text { soil } \\
\text { available }\end{array}$ & & - \\
\hline 5 & $\begin{array}{c}\text { truck } \\
\text { available }\end{array}$ & 4 & - \\
\hline 6 & $\begin{array}{c}\text { front-end } \\
\text { loader }\end{array}$ & 1 & - \\
\hline 7 & load truck & - & $7 \mathrm{~min}$. \\
\hline 8 & haul & - & $8 \mathrm{~min}$. \\
\hline 9 & $\begin{array}{c}\text { truck ready } \\
\text { to dump }\end{array}$ & - & \\
\hline 10 & dump & & $5 \mathrm{~min}$. \\
\hline 11 & \begin{tabular}{|c|} 
empty \\
truck return
\end{tabular} & & $6 \mathrm{~min}$. \\
\hline 12 & $\begin{array}{l}\text { dump } \\
\text { spotter }\end{array}$ & 1 & - \\
\hline 13 & & & - \\
\hline 14 & $\begin{array}{l}\text { dump } \\
\text { dozer }\end{array}$ & 1 & - \\
\hline 15 & spread dirt & - & $4 \mathrm{~min}$. \\
\hline 16 & counter & - & - \\
\hline 17 & & - & - \\
\hline
\end{tabular}

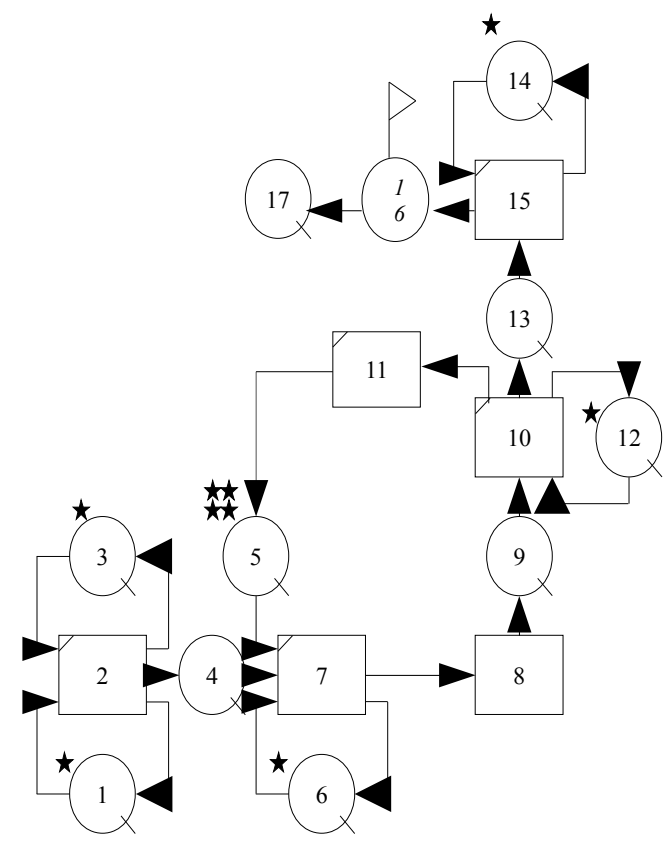

Fig. 6 CYCLONE Network 
Table 4 Performance Comparison Between COST and MicroCYCLONE

\begin{tabular}{|l|c|c|}
\hline & COST & MC \\
\hline run length (minutes) & 722 & 722 \\
\hline number of cycle & 100 & 100 \\
\hline units produced per cycle & 1 & 1 \\
\hline total production (units) & 100 & 100 \\
\hline units produced per hour & 8.31 & 8.31 \\
\hline simulation run time (sec.) & 0.65 & 9.72 \\
\hline $\begin{array}{l}\text { sensitivity analysis run } \\
\text { time required(sec.) }\end{array}$ & 6.05 & 11.12 \\
\hline
\end{tabular}

\section{CONCLUSIONS}

COST is a more reliable construction simulation program than MicroCYCLONE. It is developed based on CYCLONE that is the most widely used construction operation modeling methodology. Some unique characteristics that distinguish COST from MicroCYLONE are concluded as follows:

- COST provides a dialogue format for users to input CYCLONE model.

- COST provides more detailed schematic outputs for simulation results.

- COST adds in the fuzzy sets theory for providing capability of modeling the uncertainty for activities duration.

\section{REFERENCES}

[1] AbouRizk, S. M., and Halpin, D. W., "Probabilistic simulation studies for repetitive construction process", J. of Constr. Engrg. And Mgmt., ASCE, Vol. 116, No. 4, pp. 575-594, 1990.

[2] Bernold, L. E., and Halpin, D. W., "Microcomputer cost optimization of earth moving operation", Proc., $4^{\text {th }}$ Int. Symp. On Organization and Mgmt. Of Constr, ASCE, Vol. 11, pp., 1984.

[3] Dabbas, M. A., and Halpin, D. W., "Integrated project and process management", J. of Constr. Engrg. And Mgmt., ASCE, Vol. 108, No. 3, pp. 361-374, 1982.

[4] Halpin, D. W., and Riggs, L. S., Planning and Analysis of Construction Operations, Wiley, New York, 1992.

[5] Lutz, J. D., Halpin, D. W., and Wilson, J. R., "Simulation of learning development in repetitive construction", J. of Constr. Engrg. And Mgmt., ASCE, Vol. 120, No. 4, pp. 753-773, 1994.

[6] Huang, R. Y., and Halpin, D. W., "Visual Construction Operation Simulation: The Disco Approach", Microcomputers in Civil Engineering, Vol. 9, pp. 175-184, 1994.

[7] Halpin, D. W., MicroCYCLONE User's Manual,
Division of Construction Engineering and Management, Purdue University, West Lafayette, Ind., 1990.

[8] Liu, L. Y., and Ioannou, P. G., "Graphical objectoriented discrete event simulation system", Proc. Of Winter Simulation Conference, pp. 12851291, 1992.

[9] Martinez, J. C., and Ioannou, P. G., "Generalpurpose system for effective construction simulation", J. of Constr. Engrg. And Mgmt., ASCE, Vol. 125, No. 4, pp. 265-276, 1999.

[10] Shi, J. J, "Activity-based construction (ABC) modeling and simulation method", J. of Constr. Engrg. And Mgmt., ASCE, Vol. 125, No. 5, pp. 354-360, 1999. 